\title{
CUESTIONES DE GÉNERO EN LA MUNDIALIZACIÓN
}

\author{
ANA M ${ }^{\mathrm{a}}$ VEGA GUTIÉRREZ \\ Profesora Titular de Derecho eclesiástico \\ Universidad de La Rioja
}

\begin{abstract}
SUMARIO
1. INTRODUCCIÓN. 2. 2. UNA APROXIMACIÓN A LAS INTERRELACIONES ENTRE LA PERSPECTIVA DE GÉNERO Y LA MUNDIALIZACIÓN. 3. UN BALANCE DE LOS LOGROS ALCANZADOS EN EL ADELANTO DE LA MUJER. 4. LA CONTROVERTIDA DEFINICIÓN DE LA PERSPECTIVA DE GÉNERO. 5. CONTEXTUALIZACIÓN Y PRIORIDADES EN LAS POLÍTICAS DE ADELANTO DE LA MUJER. 6. CONCLUSIÓN.
\end{abstract}

\section{RESUMEN}

El nuevo contexto mundial inmerso en el proceso de mundialización ha ocasionado cambios que han incidido en los valores culturales, como es la cuestión del género. En la actualidad se aprecia un cambio de sensibilidad en la comunidad internacional en cuanto a la protección de los derechos de la mujer, pero no todas las mujeres se han beneficiado por igual de los efectos de la mundialización; se perciben aún diferencias significativas en la condición de las mujeres en las diversas regiones del mundo. Se constata que las leyes no son suficientes para garantizar la igualdad de los derechos desde la perspectiva del género, siendo necesaria una voluntad política más decidida a articular soluciones eficaces. Todo este fenómeno plantea problemas como la cuestión de qué parte del estatuto de la mujer ha de ser universalmente exigible, y el problema de que algunas circunstancias discriminatorias parten en realidad de un problema económico subyacente. 


\section{INTRODUCCIÓN}

El tercer milenio se estrena marcado con una clara seña de identidad: la constatación de una estrecha interdependencia de las sociedades humanas, donde los intercambios científicos, técnicos y culturales se multiplican rápidamente a escala mundial. Este fenómeno, comúnmente denominado globalización o mundialización, se presenta como un reto de consecuencias todavía imprevisibles. Acometerlo desde la interdisciplinariedad jurídica es ya un mérito de justo reconocimiento al Profesor Martínez de Pisón, coordinador del primer Seminario permanente de Profesores del Departamento de Derecho de la Universidad de La Rioja.

Me ha correspondido analizar una de esas parcelas, la relativa a las cuestiones de género. Pienso, sin presunción alguna de mi parte, que quizás sea una de las facetas más compleja y problemática, entre otras cosas, porque apela al núcleo mismo del debate suscitado por la mundialización. Sin duda, este fenómeno ha servido a los feminismos para "unirse al tren" de las reivindicaciones de los derechos a la identidad y a la diferencia, pues ningún tema como éste evidencia en mayor grado la interrelación entre los derechos humanos y la cultura, tan cuestionada y debatida en nuestros días. No en vano, como bien advierte Engle, desde la última década del siglo XX han recobrado un nuevo impulso las políticas de identidad de los años ochenta que condujeron a las mujeres, a las poblaciones indígenas y a los ciudadanos de los países del tercer mundo a cuestionar el corpus de los derechos humanos, por su aparente exclusión. La óptica de esas reivindicaciones, sin embargo, ha variado ligeramente. Ahora la discusión se centra sobre todo en los derechos del tercer mundo. Para algunos, los derechos humanos, tal y como vienen siendo interpretados y aplicados, son demasiado occidentales y liberales para poder adaptarse a las necesidades y a la cultura de esa parte del planeta. Para otros, el problema no radica en su contenido u orientación occidental sino, más bien, en que a través de esas interpretaciones se perpetúa la agenda política neoliberal de los países occidentales en perjuicio del tercer mundo ${ }^{1}$.

Esas reivindicaciones han encontrado eco y uno de sus reflejos más gráficos ha sido la atención prestada al binomio derechos humanos/cultura en la Conferencia Mundial de Derechos humanos (Viena, 14 a 25 de junio de 1993) $)^{2}$. En esa ocasión, los Estados y la entera comunidad internacional se comprometieron en la ardua tarea de armonizar la universalidad de los derechos humanos con el reconocimiento del derecho a la diferencia en sociedades cada vez más multiculturales ${ }^{3}$. Las cuestiones de género son,

\footnotetext{
1. Cfr. K. Engle, Culture and Human Rights: the Asian values debate in context, en "New York University Journal of International Law \& Politics”, 32 (2000), pp. 291-292.

2. U.N. Doc. A/CONF.157/23.

. El par. 5 de la Declaración de Viena, proclamada el 12 de julio de 1993 en esa Conferencia reconoce que «Todos los derechos humanos son universales, indivisibles e interdependientes y están relacionados entre sí. La comunidad internacional debe tratar los derechos humanos en forma global y de manera justa y equitativa, en pie de igualdad y dándoles a todos el mismo peso. Debe tenerse en cuenta la importancia de las particularidades nacionales y regionales, así como de los diversos patrimonios históricos, culturales y religiosos, pero los Estados tienen el deber, sean cuales fueren sus sistemas políticos, económicos y culturales, de promover y proteger todos los derechos humanos y las libertades fundamentales» (U.N. Doc. A/CONF.157/23).
} 
en este sentido, un buen catalizador de los logros alcanzados ${ }^{4}$. Y, desgraciadamente, la realidad delata que todavía nos queda mucho por hacer.

Aún siendo consciente que el cometido confiado es casi como "pasear en un campo minado", asumo gustosamente ese riesgo. Agradezco, por tanto, al Prof. Martínez de Pisón esta oportunidad.

\section{UNA APROXIMACIÓN A LAS INTERRELACIONES ENTRE LA PERSPECTIVA DE GÉNERO Y LA MUNDIALIZACIÓN}

La acotación del tema ofrece, en principio, una doble dificultad: por un lado, la ambigüedad del término "género", en sí mismo polisémico, lo cual dificulta una definición unívoca y universalmente compartida; por otro lado, la amplitud de las realidades que hoy abarca el concepto de mundialización. Aunque en sus orígenes fue de cuño exclusivamente economicista, en la actualidad sus significados y efectos son múltiples, como bien reflejan las diferentes intervenciones del Seminario: culturales e ideológicos, económicos y financieros, socio-políticos, ecológicos, penales, etc.

Esa evolución extensiva de su significado ha ido perfilando la distinción entre el fenómeno de la globalización, de connotaciones fundamentalmente económicas, y el de mundialización, de cariz más bien político, en cuanto tendencia que lleva a la organización de un único gobierno mundial. El primero surge con más frecuencia que el segundo en los documentos recientes de Naciones Unidas. No obstante, ambos conceptos no son incompatibles entre sí.

Con todo, y al margen de la precisiones que se hagan más adelante, la interconexión entre las cuestiones de género y la globalización/mundialización es muy estrecha. Existe una clara transversalidad recíproca entre estos dos fenómenos sociales. Basta pensar, por ejemplo, en el recurrente vínculo existente entre la persistencia de la pobreza y la desigualdad que afecta a la mujer.

La perspectiva de género, en cuanto ideología que propone una epistemología y una teoría política específicas, analiza los hechos sociales desde un enfoque particular pero con pretensiones globalizadoras. La dimensión de género, así contemplada, no es una parte integrante del conjunto sino un elemento estructurador del mismo, ya que afecta a todos y a cada uno de los hechos sociales. Se propone, en definitiva, como una clave esencial para analizar todas las realidades.

La incorporación de esta perspectiva a escala mundial es uno de los logros más importantes de la Cuarta Conferencia internacional de la Mujer, celebrada en Pekín en 1995. Hasta ese momento las sucesivas Conferencias (México, 1970; Copenhague, 1975; Nairobi, 1985) habían introducido paulatinamente un enfoque cada vez más

4. Vid., al respecto las interesantes aportaciones de CH.M. CERNA, Universality of Human Rigths and Cultural Diversity: Implementation of Human Rigts in Different Socio-Cultural Contexts, en "Human Rights Quarterly", 16 (1994), pp. 740 ss. y A. ORFORD, Contesting Globalization: A Femenist Perspective on the Future of Human Rigths, en "Transnational Law \& Contemporary Problems" 8 (1998), pp. 172 ss. 
amplio del adelanto de la mujer ${ }^{5}$. Se reconocía que su igualdad, lejos de ser una cuestión aislada, abarcaba toda la esfera de la actividad humana. Por consiguiente, era fundamental contar con su particular enfoque y su participación activa en todas las cuestiones, y no sólo en las que le afectaban únicamente a ella. En esta cadencia Pekín supuso un hito fundamental: se trasladó el centro de atención de la mujer al concepto de género, reconociendo que toda la estructura de la sociedad, y todas las relaciones entre los hombres y las mujeres en el interior de esa estructura, tenían que ser revaluadas. Únicamente mediante esa reestructuración fundamental de la sociedad y sus instituciones sería posible potenciar el papel de la mujer hasta lograr la igualdad con el hombre en todos los aspectos de la vida ${ }^{6}$.

Si trasladamos este análisis de género al terreno económico, se evidencia con más facilidad cómo el antiguo Estado social se apoyaba en un modelo patriarcal que apenas tenía en cuenta el indiscutible capital humano y económico que constituyen las mujeres $^{7}$. El nuevo Estado social del bienestar no puede prescindir de ello, de ahí la trascendencia de la puesta en marcha de una política activa que incentive los recursos destinados a la vivienda, a la educación, a la atención a la salud y al cuidado de los niños, a la reorganización de los tiempos tanto en el ámbito público como en el privado, etc. Se trata, en definitiva, de medidas que alivian el peso económico que recae sobre la mujer y contribuyen a su independencia ${ }^{8}$.

Se evidencia, pues, la relevancia de esa perspectiva de género para afrontar de manera integral la solución de los problemas socioeconómicos actuales y lograr la efectiva igualdad de las mujeres 9 .

A su vez, la globalización se presenta como un proceso de doble vertiente: intensiva, en cuanto que afecta a todas las áreas de la actividad humana, y extensiva,

5. Los textos figuran recopilados por el Instituto de la Mujer del Ministerio de Trabajo y Asuntos Sociales español en la publicación que lleva por título Las Conferencias Mundiales de Naciones Unidas sobre las mujeres, Serie Documentos, No 26, Madrid, 1999.

6. Cfr. Las cuatro conferencias mundiales sobre la mujer, 1975 a 1995: una perspectiva histórica, Departamento de Información Pública de las Naciones Unidas, New York, 2000 (DPI/2035/M-0039712-Abril 2000-7M), p. 5.

Según los cálculos de Naciones Unidas se estima que el valor de los trabajos domésticos no remunerados representa entre el 10 y el 35\% del PIB de todo el mundo. Cfr. La Mujer en una Economía Mundial en Evolución, Estudio Mundial sobre el papel de la Mujer en el Desarrollo, 1995, Naciones Unidas (S.95.IV.1).

8 La Plataforma de Acción aprobada en la IV Conferencia Mundial de la Mujer (Pekín, 1995) denuncia con claridad que «A causa de la poca atención que se ha prestado a los análisis de género, a menudo se pasan por alto la contribución y los intereses de la mujer en las estructuras económicas, tales como los mercados y las instituciones financieras, los mercados laborales, la economía como disciplina académica, la infraestructura económica y social, los sistemas fiscales y de seguridad social, así como en la familia y en el hogar. En consecuencia, es posible que muchas políticas y programas sigan contribuyendo a la desigualdad entre la mujer y el hombre. En los casos en que se ha avanzado en la integración de perspectivas de género, también ha aumentado la eficacia de los programas y las políticas» (U.N. Doc. A/CONF.177/20, par. 155).

9 . Así lo pone de manifiesto el Informe del Secretario General en el que figura la mundialización y la potenciacion de la mujer pobre entre los temas intersectoriales en los que Naciones Unidas ha decidido adoptar nuevas medidas para su adelanto. Marco para las nuevas medidads e iniciativas que podrían considerarse ante el perído extraordinario de sesiones de la Asamblea general titulado "La mujer en el año 2000: igualdad entre los géneros, desarrollo y paz para el siglo XXI”. (E/CN.6/1999/PC/2, par. 43-52, pp. 11-12). 
porque abarca todo el espacio físico del planeta. Supone, por tanto, la creación de un espacio mundial de intercambio económico, productivo, financiero, político, cultural e ideológico. Las diversas actividades económicas serían distribuidas entre los diferentes Estados. Y en la cúspide del sistema de toma de decisiones se encontrarían aquellos abocados a las tareas de producción tecnológica y de coordinación mundial. Este cuadro lleva a algunos analistas a concluir que la expansión e intensificación del poder económico ha acabado por desembocar en un "global-totalitarismo", que engulle al planeta entero y a la totalidad de los ámbitos de las relaciones humanas para integrarlas en el mercado. De este modo, globalización y neoliberalismo, a pesar de no ser sinónimos, parecen haberse aliado para hacer triunfar un único modelo económico e ideológico -el neoliberal-, con sus consiguientes riesgos y problemas. Unos y otros repercuten de forma muy especial en la mujer, como veremos después.

No cabe duda que el orden social de género, tal y como venimos describiendo, interactúa con el orden económico determinando formas específicas del impacto de los procesos de globalización y de la pobreza en mujeres y hombres ${ }^{10}$. Con todo, no es nuestro objetivo centrar el análisis de género en los procesos y efectos económicos; más bien apuntaremos a algunas de sus consecuencias en el terreno ideológico y cultural.

\section{UN BALANCE DE LOS LOGROS ALCANZADOS EN EL ADELANTO DE LA MUJER}

Aparentemente podríamos felicitarnos por los avances conseguidos en la protección de los derechos de la mujer en la segunda mitad del siglo XX. La Carta fundacional de Naciones Unidas (San Francisco, 1945) proclama en su Preámbulo el compromiso de los Estados firmantes de «reafirmar la fe en los derechos fundamentales del hombre, en la dignidad y el valor de la persona humana, en la igualdad de derechos de hombres y mujeres $(\ldots) »^{11}$. Desde luego, apunta a un importante cambio de sensibilidad en los miembros de la comunidad internacional, aunque todavía muy insuficiente ${ }^{12}$. En cualquier caso, a diferencia del resto de los compromisos asumidos en la Carta, éste era mensurable.

Los tres decenios siguientes son prolijos en Declaraciones, Pactos y Convenios internacionales que proscriben la discriminación por razón de sexo ${ }^{13}$ y tutelan de forma

10. Ofrecen un interesante análisis crítico de este problema: R. TOLDARO, Aspectos de Género de la globalización de la pobreza [http://www.un.org/womwnwatch/daw/csw/todaro.htm (última consulta: 28/4/2002)] у CH. LAMARCA, Globalización y género. Ella para él, él para el Estado y los tres para el mercado [http://www.nodo50.org/maast/documentos.htm (última consulta: 28/4/2002)]

11. Vid. también los arts. 1.3, 13.1(b), 55(c), 76(c).

12. De hecho, de los 51 Estados fundadores de Naciones Unidas y miembros originarios, sólo 30 permitían que las mujeres gozaran de los mismos derechos que el hombre.

13. Cfr. arts. 2 y 16.1 de la Declaración Universal de Derechos Humanos, de 10 de diciembre de 1948 (G.A. Res. 217); arts. 2.2 y 3 del Pacto Internacional de Derechos Económicos, Sociales y Culturales, de 16 de diciembre de 1966; arts. 2.1, 3, 23.4, 26 del Pacto Internacional de Derechos Civiles y Políticos, de 16 de diciembre de 1966; art. 14 del Convenio Europeo para la protección de los Derechos Humanos y Libertades fundamentales, del 4 de noviembre de 1950; art. 2 y 18.3 de la Carta africana de derechos humanos y de los pueblos, de 26 de junio de 1981; art. 1.1 y 17.4 de la Convención americana de los derechos humanos (Pacto de San José), del 22 de noviembre de 1969. 
específica el status de la mujer ${ }^{14}$. Pero será la Convención para la Eliminación de todas las formas de discriminación de la mujer (CEDAW), aprobada en 1979, el primer instrumento jurídico internacional que defina la discriminación contra la mujer ${ }^{15}$; aunque también sea el tratado de derechos humanos que más reservas y declaraciones estatales ha recibido, como tendremos ocasión de comprobar ${ }^{16}$.

También en el plano nacional se advierten avances, pues hoy la casi totalidad de las Constituciones de los países miembros de Naciones Unidas garantizan la igualdad y no discriminación por razón de sexo.

A pesar de todo, se perciben diferencias significativas en la condición de las mujeres en las diversas regiones del mundo enraizadas en sus respectivas estructuras políticas, económicas y sociales, en su cultura o en su religión. Lo que en unos casos son reivindicaciones de mayor bienestar para las mujeres, en otros constituyen exigencias de supervivencia. Basta analizar brevemente este desolador panorama ${ }^{17}$ :

de los 960 millones de analfabetos en el mundo dos tercios son mujeres;

en 1993 aproximadamente el 60\% de los 130 millones de niños entre 6 y 11 años que no asistían a la escuela eran niñas ${ }^{18}$;

14. Cfr. Convención para la supresión del tráfico de personas y de la explotación de la prostitución de otros, de 21 de marzo de 1950; Convención contra la Discriminación en la Educación, de 15 de diciembre de 1950; Convención relativa a la igual remuneración para trabajadores y trabajadoras por trabajo de igual valor, $\mathrm{N}^{\circ} 100$, de 29 de enero de 1951 y Recomendación $\mathrm{N}^{\mathrm{o}} 90$ de 1951; Convención relativa a la protección de la maternidad (revisada), No 103 de 1952 y Recomendación No 95 de 1952; Convención relativa al empleo de mujeres con responsabilidades familiares, $\mathrm{N}^{\circ} 123$ de 1965; Declaración sobre la eliminación de la discriminación contra la mujer, G.A. Res. 2263 (XXII), de 7 de noviembre de 1967; Convención sobre el consentimiento para el matrimonio, la edad mínima para contraer el matrimonio y el registro de los matrimonios, aprobada por A.G. Res. 1763 A (XVII), de 7 de noviembre de 1962 (entró en vigor el 9 de diciembre de 1964, de acuerdo con su art. 6); Convención sobre los derechos políticos de la mujer, adoptada y abierta a la firma y ratificación por G.A. Res. 640 (VII), de 20 de diciembre de 1952 (entró en vigor el 7 de julio de 1954, de conformidad con el art. 6); Convención sobre la nacionalidad de las mujeres casadas, de 20 de febrero de 1957; Declaración sobre la protección de la mujer y el niño en estados de emergencia o de conflicto armado, proclamada por G.A. Res. 3318 (XXIX), de 14 de diciembre de 1974; Declaración sobre la eliminación de la violencia contra la mujer, aprobada por G.A. Res 48/104 de 20 de diciembre de 1993 (U.N. Doc. A/RES/48/104).

15. En su art. 1 se indica: «A los efectos de la presente Convención, la expresión "discriminación contra la mujer" denotará toda distinción, exclusión o restricción basada en el sexo que tenga por objeto o por resultado menoscabar o anular el reconocimiento, goce o ejercicio por la mujer, independientemente de su estado civil, sobre la base de la igualdad del hombre y de la mujer, de los derechos humanos y las libertades fundamentales en las esferas política, económica, social, cultural y civil o en cualquier otra esfera».

16. La CEDAW fue adoptada y abierta a la firma, ratificación y adhesión, el 18 de diciembre de 1979 por la Asamblea General de Naciones Unidas (U.N. Doc. A/RES/34/180). Entró en vigor el 3 de septiembre de 1981, de conformidad con el art. 27.1. A fecha de 25 de julio de 2002, 170 países de los 189 Estados miembros de Naciones Unidas la habían ratificado o se habían adherido a ella. El 6 de octubre de 1999, la Asamblea General aprobó el Protocolo Facultativo de la Convención sobre la eliminación de todas las formas de discriminación contra la mujer (U.N. Doc. A/RES/54/4).

17. Transcribimos los datos difundidos por el Departamento de Información Pública de Naciones Unidas en la Cuarta Conferencia Mundial sobre la Mujer (Pekín, 1995) [DPI/1633-95 93075-February 1995-26 M].

18. Cfr. Facts and Figures, 1994-1995. UNICEF, 1995. 
92 millones de mujeres de las zonas urbanas no tienen acceso a agua potable sana y más de 133 millones de mujeres carecen de medios apropiados de saneamiento ${ }^{19}$;

el $75 \%$ de los refugiados y las personas desplazadas son mujeres y niños ${ }^{20}$;

de los 1.300 millones de personas que viven en condiciones de pobreza absoluta, más del $70 \%$ son mujeres ${ }^{21}$;

cada año se calcula que por lo menos 2 millones de niñas de 4 a 8 años sufren mutilación genital en Africa, Asia o como inmigrantes o refugiadas en América del Norte y Europa, lo que representa unas 6.000 cada día. Se calcula, según los expertos, que este fenómeno afecta a 134 millones de mujeres ${ }^{22}$;

de un grupo de 640 familias de una comunidad de Asia meridional, el 51\% admitieron que habían matado a una hija durante la semana siguiente al nacimiento ${ }^{23}$;

mueren entre 60 y 100 millones de niñas en todo el mundo como consecuencia de la falta de atención física ${ }^{24}$;

cada 8 segundos una mujer es objeto de malos tratos y cada 6 minutos una mujer es violada en Estados Unidos de América ${ }^{25}$;

la mayoría de las mujeres siguen ganando salarios que sólo suponen del 50 al 80\% de los salarios masculinos ${ }^{26}$;

en 1994 sólo 3 países tenían un 30\% de mujeres en puestos decisorios ${ }^{27}$ y sólo 24 mujeres habían sido elegidas Jefas de Estado o de Gobierno en este siglo, la mitad de ellas después de $1990^{28}$;

en sólo 16 países las mujeres ocupan el $25 \%$ o más de los escaños parlamentarios, según la estadísticas de la Unión Interparlamentaria.

La lista podría completarse con las referencias a las violaciones sistemáticas como arma de guerra (se estiman en 20.000 las víctimas del conflicto de los Balcanes), los programas de control de población que imponen esterilizaciones o abortos forzados o conllevan, como efecto indirecto, el infanticidio femenino, la poligamia, el acoso sexual

19. Cfr. La mujer en el mundo, 1995: tendencias y estadísticas, Naciones Unidas, New York, 1995.

20. Cfr. WISTAT, 1994 y ACNUR, 1995.

21. Cfr. Informe sobre el desarrollo humano, UNDP, 1995.

22. Cfr. Nahid Toubia, Female Genital Mutilation: A Call for Global Action, 1993. Esas cifras figuran también en el preámbulo de la proposición de ley remitida por el Senado al Congreso de Diputados para reformar el art. 149 de la L.O. 10/1995, de 23 de noviembre, del Código Penal, a fin de introducir una cláusula interpretativa sobre la represión de la mutilación genital femenina. Cfr. Proposición de ley 124/000003, en Boletín Oficial de las Cortes Generales, de 23 de julio de 2001, Serie B. Núm. 161-1.

23. Cfr. Facts and Figures, 1994-1995, cit.

24. Cfr. Girls and Women: A UNICEF Development Priority, UNICEF, 1993.

25. Cfr. Datos del Centro Nacional de legislación sobre la Mujer y la Familia de Estados Unidos de América (1988), publicados por el The New York Times, el 19 de octubre de 1995.

26. Cfr. La Mujer en una Economía Mundial en Evolución, cit.

27. Cfr. Segundo examen y evaluación de las estrategias de Nairobi orienatdas hacia el futuro para el adelanto de la mujer, Naciones Unidas, 1995.

28. Cfr. La mujer en el mundo 1990-1995: tendencias y estadísticas, Naciones Unidas, 1995 (S.95.XVII.2). 
en el trabajo, la explotación sexual infantil, la trata de blancas, la existencia de redes internacionales de prostitución de refugiadas e inmigrantes, etc.

Las leyes no bastan por sí mismas para garantizar la igualdad de sus derechos. Las Naciones Unidas han tomado cada vez más conciencia de sus dificultades y a través de las sucesivas Conferencias internacionales sobre la mujer se han ido elaborando estrategias y planes de acción universales y regionales con el fin de asegurarles los mismos derechos, oportunidades y responsabilidades, de modo que estén capacitadas para desarrollar sus talentos y capacidades para su propia realización personal y en beneficio de la sociedad. Sin embargo, las mejoras en la situación jurídica y social de la mujer y los esfuerzos por reducir la discriminación únicamente habían beneficiado a una pequeña minoría y no habían podido cambiar la estructura básica de desigualdad en las relaciones entre el hombre y la mujer. La comprensión de esta situación obligó a adoptar un nuevo enfoque.

Como apuntábamos más arriba, la Declaración y la Plataforma de Acción aprobadas en la IV Conferencia Internacional de la Mujer (Pekín, 1995) asumieron ese reto. Identificaron doce áreas de especial preocupación que representan los principales obstáculos al adelanto de la mujer y que exigían la adopción de medidas concretas por parte de los gobiernos y de la sociedad civil: pobreza, educación y capacitación, salud, violencia, conflictos armados, economía, participación en el poder y en la adopción de decisiones, mecanismos institucionales para el adelanto de la mujer, sus derechos humanos, medio ambiente y la niña. La IV Conferencia reafirmó que los derechos humanos de las mujeres y de las niñas eran parte inalienable, integrante e indivisible de los derechos humanos universales ${ }^{29}$ y estableció varios objetivos estratégicos para asegurar que gozan de la totalidad de los derechos humanos.

Los gobiernos, al aprobar esos documentos, se comprometían a incluir de manera efectiva una perspectiva de género en todas sus instituciones, políticas, procesos de planificación y adopción de decisiones ${ }^{30}$. Esto significaba que, a partir de entonces, antes de tomar decisiones o ejecutar planes, deberían analizarse sus efectos sobre los hombres y las mujeres, y sus respectivas necesidades. La incorporación de esa nueva dimensión exigía que se examinara nuevamente la sociedad en su totalidad y su estructura básica de desigualdad. Por consiguiente, la atención no se centraba únicamente en la condición jurídica y social de la mujer, sino que se dirigía a reestructurar las instituciones y la adopción de decisiones políticas y económicas en el conjunto de la sociedad. La integración de esta perspectiva de género viene siendo,

29. Cfr. par. 9 de la Declaración de Beijing, aprobada en la $16^{\mathrm{a}}$ sesión plenaria, celebrada el 15 de septiembre de 1995 (U.N. Doc. A/CONF.177/20/Add. 1)

30. En el parágrafo 38 de la Declaración de Beijing, cit., se afirma: «Por la presente nos comprometemos en calidad de Gobiernos a aplicar la siguiente Plataforma de Acción y a garantizar que todas nuestras políticas y programas reflejen una perspectiva de género. Instamos al sistema de las Naciones Unidas, a las instituciones financieras regionales e internacionales y a las demás instituciones regionales e internacionales pertinentes, a todas las mujeres y todos los hombres, así como a las organizaciones no gubernamentales, con pleno respeto de su autonomía, y a todos los sectores de la sociedad civil a que, en cooperación con los gobiernos, se comprometan plenamente y contribuyan a la aplicación de esta Plataforma de Acción». 
desde entonces, una pauta generalizada en todas las Conferencias mundiales celebradas con posterioridad ${ }^{31}$.

El interés de Naciones Unidas en evaluar la eficacia del nuevo sistema se ha traducido, entre otras medidas, en un estrecho seguimiento de la aplicación de los objetivos marcados por la IV Conferencia. Con este fin el Consejo Económico y Social aprobó en su resolución 1996/34 el Plan para el adelanto de la mujer (1996-2000) mediante el cual el sistema de las Naciones Unidas se comprometía a promover y defender el ejercicio cabal por la mujer, en condiciones de igualdad, de todos los derechos humanos, en particular los derechos relacionados con algunos sectores tales como el empleo, la educación, la violencia contra la mujer y el derecho a la salud y la procreación, así como en las actividades de desarrollo. Y en esta misma línea, la Asamblea General convocó un período extraordinario de sesiones en Nueva York, del 5 al 9 de junio de 2000, cuyo tema central fue "La mujer en el año 2000: igualdad entre géneros, desarrollo y paz en el siglo XXI"32. Sin duda, muchas cosas están cambiando, pero todavía queda mucho por hacer.

Hay, desde luego, una nueva concienciación internacional y estatal sobre la desigualdad de la mujer y una voluntad política más decidida a articular soluciones eficaces para intentar eliminarla. Un dato interesante que así lo corrobora, es la reciente incorporación al texto constitucional de diversos Estados de la prohibición de discriminaciones basadas en razones de género, y no de sexo, como hasta ahora venía siendo común ${ }^{33}$.

Más obvio, por más contundente, es al respecto el Estatuto de la Corte Penal Internacional $^{\mathbf{3 4}}$. Por primera vez en la historia, un tribunal con jurisdicción penal internacional, complementaria a las nacionales, incorpora las cuestiones de género al definir los crímenes sometidos a su competencia. De esta forma, quedan comprendidas dentro del delito de genocidio las medidas destinadas a impedir nacimientos en el seno de un grupo nacional, étnico, racial o religioso ${ }^{35}$. A su vez, los crímenes de lesa humanidad incluyen la violación, la esclavitud sexual, la prostitución forzada, el embarazo forzado, la esterilización forzada u otros abusos de gravedad comparable ${ }^{36} \mathrm{y}$ la persecución de un grupo o colectividad con identidad propia fundada en motivos de género $^{37}$. Por último, también se castigan como crímenes de guerra: la violación, la esclavitud sexual, la prostitución forzada, el embarazo forzado, la esterilización forzada

31. Cfr. Cumbre Mundial sobre Desarrollo social, Copenhague, 6-12 marzo 1995, (U.N. Doc. A/CONF. 166/9); Conferencia de las Naciones Unidas sobre los asentamientos humanos (Habitat II), Estambul, 3-14 junio 1996 (U.N. Doc. A/CONF. 165/14).

32. Ofrece una información muy completa al respecto el Informe del Secretario General de Naciones Unidas sobre Examen y evaluación de la aplicación de la Plataforma de Acción de Beijing (U.N. Doc. E/CN.6/2000/PC/2).

33. Tal es el caso de las constituciones de los siguientes países: art. 23 de Zimbadwe (1979, reformada en el 2000); art. 15.3 de Kirguistán (1993); art. 13.a de Malawi (1995); art. 16.2.c de Sudáfrica (1997); art. 8.1 de Somalia (2001) y art. 11.2 a) de Sri Lanka (2000).

34. El Estatuto de Roma de la Corte Penal Internacional fue adoptado el 17 de julio de 1998 por la Conferencia Diplomática de Plenipotenciarios, reunida en Roma del 15 de junio al 17 julio de 1998, por 120 votos a favor, 7 en contra y 21 abstenciones, para ser abierto inmediatamente a firma. Entró en vigor el 1 de julio de 2002, de acuerdo a su artículo 126 (cfr. U.N. Doc. A/CONF.183/9).

35. Cfr. Ibid., art. 6 d).

36. Cfr. Ibid., art. $7.1 \mathrm{~g})$.

37. Cfr. Ibid., art. $7.1 \mathrm{~h}$ ). 
y cualquier otra forma de violencia sexual que constituya una violación grave de los Convenios de Ginebra de 12 de agosto de $1949^{38}$.

Estos logros son sólo una pequeña muestra de los paulatinos avances para promover la participación equitativa de la mujer y la igualdad, abordarlos en su integridad excede a las pretensiones de nuestra investigación. A pesar de todo, la incorporación de esta perspectiva de género no está resultando una tarea fácil. A las dificultades que comporta todo cambio se añaden otras de mayor calado ideológico. La primera de ellas, anunciada al principio, es la propia definición y alcance del término género.

\section{LA CONTROVERTIDA DEFINICIÓN DE LA PERSPECTIVA DE GÉNERO}

El término género comenzó a ser utilizado en los años 60 y fue desarrollado después por la psicología y la antropología, especialmente por la escuela constructivista. Los llamados "feminismos de la segunda ola" (el liberal, el marxista y el psicoanalista $)^{39}$ contribuyeron de forma decisiva a su consolidación. Todos ellos evidenciaron desde sus respectivas orientaciones epistemológicas la significativa distancia que media entre el sexo y el género, y lo hicieron desde posiciones ciertamente críticas $^{40}$.

Una primera aproximación conceptual nos conduce a identificar el sexo con el status biológico de una persona en cuanto varón o mujer ${ }^{41}$; se refiere, por tanto, a las categorías biológicas de hombre o mujer designadas sobre la base de las características anatómicas y/o la correspondiente díada cromósomica. Mientras que el género alude a los roles o estereotipos asignados a cada uno de los sexos en cada sociedad; subraya, pues, el aspecto cultural. Incluso, perfilando todavía más el término, podemos afirmar que se trata de una contrucción cultural. Según esta teoría del género, «las diferencias entre hombres y mujeres que se manifiestan como antagónicas, no dependen de la naturaleza biológica o social de cada sexo, sino que son el resultado de procesos de

38. Cfr. Ibid., art. 8.2 b) xxii y 8.2 e) vi.

39. Ofrecen una buena síntesis de sus premisas metodológicas: F. ARRANZ LozANO, De la uniformidad a la diversidad reivindicativa: una introducción a la teoría feminista, en P. ROMÁN Y J. FERRI (eds.), Los movimientos sociales. Conciencia y acción de una sociedad politizada, Madrid, 2001, pp. 145-150 y G. SOLÉ, Historia del feminismo (siglos XIX y XX), Pamplona 1995, pp. 50 ss.

40. Sus máximas exponentes fueron S. DE BEAUVOIR, Le Dexième sexe, Paris, 1949 y B. FrIEDAN, The Feminine Mystique, New York, 1963. La primera, desde la dialéctica hegeliana de la autoconciencia y el existencialismo se cuestiona los elementos que han configurado la femenidad para llegar a concluir que el sexo es una construcción cultural, más que un don de la naturaleza. La auténtica libertad de las mujeres pasa por una revisión sobre su específica biología, como la clave para entrar en el ámbito de la razón y de la cultura. La maternidad, desde su punto de vista, al quedar envuelta dentro del matrimonio y de la familia, es una desventaja y una trampa porque las afianza a los dictados de una sociedad patriarcal. La segunda critica a las mujeres el haber obedecido a los mandatos sociales que las exigían ser buenas madres y esposas confinándolas al ámbito privado, de ahí que reclame una mayor educación para las mujeres y su incorporación al mundo laboral.

El cuadro se completa con las aportaciones del psioanálisis femenino que instan a la revisión de algunos principios biologicistas, como el de mantener que la anatomía es el destino y atribuyen a la biología la causa principal de la subordinación de la mujer. Vid., S. FIRESTONE, The Dialectic of Sex, New York, 1972.

41. Cfr. American Psyquiatric Association, Manual diagnóstico y estadístico de los trastornos mentales (DSM IV), Washington, 1995. 
construcción social mediante los cuales se adjudican simbólicamente las expectativas y los valores que cada cultura atribuye a sus varones y hembras» ${ }^{42}$. Esos roles de género masculinos y femeninos se aprenden en las familias y comunidades, y varían de una cultura a otra, y de una generación a otra ${ }^{43}$.

Planteados así ambos términos, es fácil percibir que el alcance de la discriminación por razón de género es mucho mayor que el motivado por el sexo. La finalidad subyaciente del principio de la igualdad de género es la erradicación de las "discapacidades" impuestas a las mujeres basándose en las definiciones culturales de su rol en la sociedad, y no meramente una discriminación fundada en su capacidad reproductiva o en sus rasgos biológicos ${ }^{44}$.

Ciertamente, este sistema binario sexo/género puede ser muy útil para discernir los aspectos biológicos de la sexualidad -lo aportado por la naturaleza-, de aquellos otros construidos culturalmente. Pero conlleva no pocos riesgos y evidentes dificultades, pues, entre otras cosas, exige reasignar las funciones y los roles tradicionalmente vinculados a cada sexo dentro de la familia y de la sociedad para lograr alcanzar una verdadera corresponsabilidad del hombre y de la mujer en todos los ámbitos de la vida. Se trataría, pues, de concienciar a los ciudadanos, a los políticos y a los legisladores de que su percepción de la realidad ha sido fabricada por la sociedad y es absolutamente mutable ${ }^{45}$.

Esta epistemología jurídica, de marcado cuño constructivista, parte de una premisa clara, enunciada con gran precisión, entre otros, por Martínez García. En su opinión, «el derecho ejerce una poderosa capacidad de definir la realidad, de conformarla; (...) ostenta un poder de demarcación de la realidad y determina no sólo cómo deben ser las cosas sino también cómo son. El derecho decide cuál es la realidad que cuenta para él, qué es lo que existe o no jurídicamente. (...) La realidad jurídica es, por tanto, una realidad inventada, y la realidad de la que el derecho surge y a la que se aplica es también un invento del mismo derecho» ${ }^{46}$. En definitiva, según este particular punto de vista, la realidad jurídica es esencialmente convencional.

Las consecuencias sociojurídicas de esa afirmación son muchas y especialmente complejas cuando las proyectamos sobre las cuestiones de género. Pensemos, por ejemplo, en lo que prescribe el art. 5 de la CEDAW: «Los Estados Partes tomarán medidas apropiadas para: a) modificar los patrones socioculturales de conducta de hombres y mujeres, con miras a alcanzar la eliminación de los prejuicios y las prácticas consuetudinarias y de cualquier otra índole que estén basados en la idea de inferioridad

42. R. Bergalli y E. Bodelón, La cuestión de las mujeres y el Derecho penal simbólico, en “Anuario de Filosofía del Derecho", 9 (1992), pp. 43-67, cit. por J.I. LACASTA ZABALZA, Género y ambivalencia del Derecho y su sistema penal, en AA.VV., Análisis del Código Penal desde la perspectiva de género, Vitoria, 1998, p. 18.

43. Cfr. Gender: A Working Definition, en Women's Health and Development Programme, World Health Organization (WHO), Geneva, 1998.

44. Sobre el alcance de esta distinción, vid. D.J. Sullivan, Gender equality and religious freedom: toward a framework for conflic resolution, en "Journal of International Law and Politcs", 24 (1992), pp. 797-805.

45. Describe este proceso de deconstrucción del género J.C. WiLLIAMS, Deconstructing Gender, en P. SMith (ed.), Feminist Jurisprudence, New York/Oxford, 1993, pp. 531-559.

46. J.I. MARTínez GARCÍA, La imaginación jurídica, Madrid, 1993, pp. 33-37, cit. por J.I. LACASTA ZABALZA, Género y ambivalencia del Derecho..., cit., p. 22. 
o superioridad de cualquiera de los sexos o en funciones estereotipadas de hombres y mujeres $(\ldots){ }^{47}$. Ahora bien, ¿quién decide, y cómo, el "patrón o la construcción cultural" para llevar a cabo la reasignación de roles del hombre y de la mujer propugnada?, ¿cómo diferenciar entre la legitimidad de la opción libre de la esposa de un polígamo y la de una lesbiana que se insemina para tener un hijo y constituir una familia?, ¿acaso es posible ignorar las diversas identidades culturales y sugerir un modelo uniforme?

Lo cierto es que ni siquiera hoy, en el seno del movimiento feminista, «se puede, ni se debe llegar a acuerdo alguno sobre la unificación de significados o contenidos que encierren al feminismo en cosmovisiones o propuestas excluyentes», como bien apunta Arranz ${ }^{48}$. Mientras que para algunos sectores, reflejados incluso en ciertas posiciones estatales, la cultura debería servir para limitar los derechos de las mujeres que están en conflicto con ella; para otros, la cultura debería modificarse para lograr protegerlos ${ }^{49}$. Como puede comprobarse, las cuestiones de género conectan de lleno con la multiculturalidad en cuanto política que no se limita a respetar las diferencias que encuentra sino que las promueve e incluso las fabrica (recordemos, sin ir mas lejos, la tesis de Martínez García citada unas líneas antes). Ciertamente, en muchas ocasiones la identidad se reivindica a partir de discriminaciones, humillaciones o agravios de una manera comprensible pero sesgada, apelando a supuestos derechos a la diferencia. Pero, «¿cuál es, llegados a este punto, la lógica que establece cuáles son las "diferencias importantes"?», se cuestiona con acierto Sartori. Compartimos con él «que en este punto el porqué lógico deja paso a esta explicación práctica: que las diferencias que cuentan son cada vez más las diferencias puestas en evidencia por el que sabe hacer ruido y se sabe movilizar para favorecer o dañar intereses económicos o intereses electorales. El tema, es entonces, que ahora ya es casi imposible encontrar —en este laberinto de "diferencias reconocidas" - un criterio objetivo y coherente que las determine» ${ }^{50}$.

Aquí radica el punctum dolens del debate suscitado por la incorporación de la perspectiva de género en el contexto de la mundialización. Su salto a la escena jurídicopolítica internacional de forma oficial tuvo lugar en 1995, en la ya citada IV Conferencia Mundial de la Mujer. El término género aparecía mencionado en el borrador unas ciento cincuenta y cinco veces, de las cuales al menos cuarenta aludían de forma expresa a "la perspectiva de género". Su traducción al francés y al español provocó un intenso debate porque el lobby feminista y algunas delegaciones estatales se negaron a que fuera traducido por $\operatorname{sexo}^{51}$. Hubo, incluso, que constituir un grupo de

47. Plantearon reservas a este artículo: Francia, India, Malasia, Nueva Zelanda y Níger.

48. F. ARranz LOZANo, De la uniformidad a la diversidad reivindicativa ..., cit., p. 137.

49. Sobre este debate vid. K. EnGLe, Culture and Human Rights: the Asian values debate in context, cit., pp. 294-297, con la bibliografía allí citada.

50. G. SARTORI, La sociedad multiétnica. Pluralismo, multiculturalismo y extranjeros, Madrid, 2001 , p. 87.

51. Así lo subrayó Bella Abzug, feminista "histórica" y ex-miembro del Congreso de los Estados Unidos, en su discurso a los delegados estatales en Nueva York, el 3 de abril de 1995: «No se nos forzará a volver al concepto "biologia = destino" que busca definir, confinar y reducir a las mujeres a sus características sexuales físicas. El sentido de la palabra género ha evolucionado y se distingue del término sexo para expresar que los roles y las posiciones sociales de los hombres y de las mujeres están definidos por la sociedad y, en consecuencia, están sometidos a cambio (...). Varios Estados-miembros tratan desde hace algún tiempo de eliminar la palabra género de nuestro Plan de Acción; sustituirla por 
contacto oficioso en el seno de la propia Conferencia para aclarar y definir su significado. La respuesta fue, sin embargo, lacónica y deliberadamente ambigua ${ }^{52}$, a pesar de ser la primera vez en la que este término figuraba en un documento internacional -bien es verdad que sin fuerza jurídica vinculante- de gran trascendencia para el diseño de las políticas de adelanto de la mujer y en contextos clave para el reconocimiento de algunos derechos humanos, como la vida, la salud o la familia ${ }^{53}$. Como resultado, varios Estados interpusieron reservas y declaraciones al texto final de la Plataforma de Acción, postura que se repitió después en otras Conferencias internacionales ${ }^{54}$.

El problema conceptual, más que terminológico, suscitado por la perspectiva de género se reabrió de nuevo con motivo de la aprobación del Estatuto de la Corte Penal Internacional; y se solventó incluyendo su definición en el articulado: «a los efectos del presente Estatuto -se indica en el art. 7.3- se entenderá que el término "género" se

el término sexo es un insulto y una tentativa execrable de derribar las conquistas de las mujeres, de intimidar y bloquear todo progreso de futuro». Texto tomado de D. O'LEARY, "Gender". La déconstruction de la femme. Documento difundido durante la IV Conferencia Mundial de la Mujer, Beijing, 1995, p. 7.

52. La Presidenta de la Conferencia, Gertrude Mongella, hizo público el resultado de ese informe durante el transcurso de la misma. Como allí se indicaba: «la palabra género tal y como se emplea en la Plataforma de Acción de la IV Conferencia Mundial sobre la Mujer debe interpretarse y comprenderse igual que en su uso ordinario y generalmente aceptado» [Declaración de la Presidenta de la Conferencia sobre la interpretación más generalizada del término "género", (U.N. Doc. A/CONF.177/20/Add.1, n. 3, p. 47)].

53. Nos hemos ocupado de esta problemática en A.Ma VEGA GUTIÉRreZ, Políticas familiares en un mundo globalizado, Pamplona, 2002.

54. Plantearon reservas al término género en la Plataforma de Acción de la IV Conferencia Mundial sobre la Mujer: Paraguay (U.N. Doc. A/CONF.177/20, Cap. V, n. 25), Guatemala y la Santa Sede. El argumento esgrimido por Guatemala fue el siguiente: «En apego a los criterios éticos, morales, legales, culturales y naturales de la población guatemalteca, interpreta el concepto género únicamente como género femenino y género masculino para referirse a mujeres y hombres y se reserva la interpretación de la expresión "estilo de vida", por no estar claro su significado en estos documentos» (Ibid., n. 10). La Santa Sede incluyó una declaración en virtud de la cual «entiende la palabra "género" sobre la base de la identidad sexual biológica, masculina o femenina (...). La Santa Sede excluye así las interpretaciones dudosas basadas en puntos de vista dudosos por los que se afirma que la identidad sexual puede adaptarse indefinidamente con fines nuevos y diferentes. También se disocia de la noción biológica determinista de que las funciones y las relaciones de ambos sexos están determinadas de manera única y estática. El Papa Juan Pablo insiste en el carácter distintivo y complementario del hombre y la mujer. Al mismo tiempo, ha aplaudido la asunción de nuevas funciones por la mujer, ha subrayado el grado en que el condicionamiento cultural ha sido un obstáculo para su progreso y ha exhortado a los hombres a contribuir al "gran proceso de liberación de la mujer" (Carta a la Mujer, 6) (...)» (Ibid., n. 11).

En el Informe de la Conferencia de las Naciones Unidas sobre los asentamientos humanos (Habitat II), Estambul, 3-14 junio 1996 (U.N. Doc. A/CONF. 165/14, cap. VIII) interpusieron reservas e incluyeron declaraciones: la Santa Sede (ibid., n. 9) y Guatemala, que ratificó en su totalidad las reservas en las anteriores Conferencias Mundiales, «especialmente en lo que se refiere a la interpretación del concepto "género" únicamente como género masculino y género femenino, es decir a lo que se refiere a hombres y mujeres» (ibid., n. 8); y la República Islámica del Irán, que defendió la interpretación «de los conceptos y frases como "género" (...) de acuerdo con la ley cherámica y los valores éticos y espirituales de la sociedad islámica, que respetará plenamente» (ibid., n. 11). La delegación de Zambia se reservó «su posición sobre toda la terminología que esté en contradicción con los principios del cristianismo y en desacuerdo con sus valores y tradiciones culturales y espirituales». Y expresó sus reservas «con respecto a la palabra "género", a menos que se entienda que se refiere a la identidad sexual biológica del hombre y la mujer» (ibid., n. 20). 
refiere a los dos sexos, masculino y femenino, en el contexto de la sociedad. El término "género" no tendrá más acepción que la que antecede» ${ }^{55}$.

\section{CONTEXTUALIZACIÓN Y PRIORIDADES EN LAS POLÍTICAS DE ADELANTO DE LA MUJER}

El fondo de la viva polémica radica, precisamente, en determinar qué parte del estatuto de la mujer ha de ser universalmente exigible, en cuanto intangible, por corresponder a su inalienable dignidad humana, y qué parte, por el contrario, es negociable e incluso tolerable, por responder a una determinada construcción cultural, aunque no sea compartida ni entendida por el resto de países. Una delimitación poco obvia, si atendemos a los intensos debates entre las delegaciones estatales que asistieron a la IV Conferencia Mundial de la Mujer. En realidad, en aquella ocasión, al igual que ocurriría después en las sucesivas Conferencias internacionales, volvió a reproducirse el desacuerdo - la evidente falta de consenso- que años antes se había evidenciado al aprobar la $\mathrm{CEDAW}^{56}$. Un desacuerdo que todavía pervive, si atendemos al número y al contenido de las reservas planteadas por los Estados ${ }^{57}$.

La mayoría de ellas - treinta y una, concretamente- aluden a las cláusulas sobre arreglo de controversias acerca de interpretación o aplicación de la Convención (art. 29), lo cual no deja de ser significativo, pues muestra las reticencias de los Estados a comprometer parcelas de su soberanía en un terreno delicado y potencialmente muy conflictivo. Le siguen en importancia numérica las reservas que guardan relación con la igualdad de la mujer en el derecho de familia (art. 16), con un total de veinticinco; con idéntico número (doce) figuran las que se refieren a las obligaciones de los Estados Partes (art. 2) y a la igualdad en las leyes de nacionalidad (art. 9). Todas ellas apelan a diferentes aspectos culturales del estatuto de la mujer muy arraigados en sus respectivas civilizaciones, aunque no todos de igual trascendencia jurídica para el adelanto de la mujer: el derecho a elegir apellido, orden sucesorio a la Corona, reparto de herencia, status jurídico matrimonial, capacidad jurídica de obrar, etc.

Como es obvio, el fundamento que subyace en cada una de ellas difiere notoriamente. En algunos casos la discriminación de la mujer es manifiesta, e incluso se ve reflejada de forma expresa en sus ordenamientos jurídicos, como ocurre en varios

55. El Estatuto recurre al género en diversas ocasiones y en contextos diferentes. En unos casos, el término engloba el binomio sexo/género, como ocurre en el art. 7.1(h), al definir una de las conductas subsumibles en el tipo penal de crímenes de lesa humanidad, en concreto, la persecución de un grupo o colectividad con identidad propia fundad en motivos de género; o en el art. 21.3, para asegurar su aplicación e interpretación sin distinciones por razón de género. Por el contrario, en otros casos, la distinción sexo/género queda explícitamente subrayada, como puede apreciarse en los artículos que aluden a la violencia sexual y por razones de género (cfr. arts 42.9, 54.1(b), 68.1).

56. Acerca del diverso fundamento ideológico de dichas reservas y de las correspondientes estrategias políticas subyacentes, vid. R.J. CoOK, Reservations to the Convention on the Elimination of All Forms of Discrimination Against Women, en "Virginia Journal of International Law" 30/3 (1990), pp. 643-716; M. Elósegui, Diez temas de género. Hombre y mujer ante los derechos productivos y reproductivos, Madrid, 2002, pp. 92-113.

57. A fecha de 20 de diciembre de 2000, el número de Reservas y Declaraciones interpuestas era de 132, planteadas por 49 Estados partes. Un 76\% sobre el total eran de carácter sustantivo o normativo, y un $24 \%$, de carácter procedimental. Cfr. Reservations and Declarations to the Human Rights Treaties [http://www.bayefsky.com/report/annex5.php (consulta: 27/02/2003)]. 
países islámicos ${ }^{58}$. Aunque las recientes presiones internacionales estén logrando algunas mitigaciones en sus sistemas legales, todavía, como es lógico, no las han hecho desaparecer de la práctica social, ni de los usos y costumbres tradicionales. En otros casos, los países, desechando la subordinación de la mujer, fundan sus reservas en el rechazo al modelo neoliberal de absoluta autonomía y emancipación de la mujer propugnado por el feminismo radical e inspirador de algunos artículos de la CEDAW, sobre todo de los relacionados con el derecho a la salud y la maternidad (cfr. arts. 12 y $16)^{59}$. Estos Estados abogan por una mayor corresponsabilidad del varón, pues su problema real no es la independencia de la mujer sino sus consecuencias: una grave feminización de la pobreza motivada porque las mujeres han afrontar en solitario la educación y crianza de los hijos. Tal es la situación de numerosos países de África e Iberoamérica $^{60}$.

Por otra parte, como se ha dicho con acierto, algunas de esas reservas no obedecen a razones ideológicas sino económicas, pues ciertos Estados no pueden o no quieren asumir la inversión que supone la aceptación de algunos de los compromisos que exige la adhesión a la $\mathrm{CEDAW}^{61}$; especialmente en lo que se refiere al acceso gratuito a la educación y a la sanidad (art. 13), o al derecho al trabajo (art. 11). Y en este punto la historia se repite, como bien lo demuestran las intensas negociaciones en el seno de las Conferencias Mundiales celebradas en la década de los noventa, en especial en las de Población y Desarrollo (El Cairo, 1994) ${ }^{62}$, Desarrollo Social (Copenhague, 1995) ${ }^{63}$ y la Mujer (Pekín, 1995) ${ }^{64}$.

En todos estos casos no deja de sorprender que precisamente algunas de las delegaciones estatales que más presionaron a otras para que llevaran a cabo cambios legislativos y culturales en determinados campos que consideran discriminatorios para la mujer, no estén dispuestos a contribuir económicamente con ellos ${ }^{65}$. «Moralizar,

58. Cfr. Z. CombalíA, El derecho de libertad religiosa en el mundo islámico, Pamplona, 2001, pp. 125-132, 139-140; B.A. VenKTRAMEN, Islamic States and the United Nations Convention on the Elimination of All Forms of Discrimination Against Women: are the Shari'a and the Convention Compatible?, en "Americam University International Law Review” 44 (1995), pp. 1949-2027; A. JENEFSKY, Permissibility of Egypt's Reservations to the Convention on the Elimination of All Forms of Discrimination Against Women, "Maryland Journal of International Law and Trade" 15 (1991), pp. 199233.

59. No han faltado interpretaciones que amparándose en tales artículos reivindican ciertas libertades como nuevos derechos; tal es el caso, por ejemplo, de los llamados derechos reproductivos. Sobre su contenido y alcance, vid., A.M ${ }^{\mathrm{a}}$ VEGA GUTIÉRREZ, Los derechos reproductivos en la sociedad postmoderna: ¿una defensa o una amenaza contra el derecho a la vida?, en Derechos reproductivos y técnicas de reproducción asistida, (coord. J. VIDAL MARTíNEZ), Granada, 1998, pp. 1-52.

60. Comparto, en este sentido, las tesis de M. ElósEgui, Diez temas de género..., cit., pp. 107-113.

61. Ibid., p. 103.

62. Cfr. U.N. Doc. A/CONF.171/13.

63. Cfr. U.N. Doc. A/CONF. 166/9.

64. Cfr. U.N. Doc. A/CONF.177/20.

65. Para ilustrar cuanto venimos diciendo basta examinar el caso de Estados Unidos. Su tenaz intervención a favor de la aprobación de los derechos reproductivos y de la intensificación de programas de control de población en los países en vías de desarrollo durante las Conferencias internacionales de Población y Desarrollo y de la Mujer, contrastan con sus reticencias económicas para apoyar su desarrollo social. El contenido de su reserva al texto final del Programa de Acción de la Cumbre Mundial sobre el Desarrollo Social (Copenhague, 1995) fue el siguiente: "Como declararon los Estados Unidos varias veces durante la Cumbre Mundial sobre el Desarrollo Social y en el curso de los preparativos de la Cumbre, debido a limitaciones financieras internas no puede convenir en aumentar la 
cuando no cuesta, resulta fácil -acusa con razón Tamir, aludiendo a las políticas encaminadas a eliminar la práctica de las mutilaciones genitales--. Es mucho más difícil recabar los medios necesarios para educar a la mujer y de esta forma capacitarla para defender su nivel de vida» ${ }^{66}$.

Luchar contra el analfabetismo, la pobreza y la explotación que perpetúan muchas de esas prácticas discriminatorias demanda un generoso esfuerzo económico en los países afligidos, que los Estados occidentales se resisten a ofrecer. Por el contrario, se tiene la impresión de que su agenda política para incorporar la perspectiva de género discurre por derroteros bien diversos. Los feminismos del norte parecen concentrar gran parte de sus esfuerzos en hacer triunfar la ideología hiperindividualista del neoliberalismo, introduciendo nuevos derechos emancipadores de la mujer, tales como el de la salud sexual y reproductiva, el derecho a un hijo, el derecho a la libre orientación sexual, o a elegir entre una pluralidad de formas de familia ${ }^{67}$. Vierten en la escena internacional conceptos novedosos y ambiguos (maternidad sin riesgo, abortos seguros, contracepción de emergencia, salud sexual y reproductiva de los adolescentes, etc.) para justificar e intensificar programas de control de población sobre los países en vías de desarrollo, de muy dudosa legitimidad, como se ha podido comprobar en las campañas de esterilizaciones abusivas de Perú o México ${ }^{68}$. No es una casualidad que la principal promotora de esos cambios haya sido la International Planned Parenthood Federation (IPPF), que en 1996 publicó la Carta sobre derechos reproductivos, donde -como bien apunta Elósegui- «presenta su interpretación de los derechos humanos, y en concreto los derechos reproductivos como la interpretación por antonomasia» ${ }^{69}$. Para llevar a cabo su estrategia no le faltan importantes apoyos financieros de diversos Estados (Canadá, Japón, Bélgica, Finlandia, Malasia, Suecia, Reino Unido, Surinam) y

asistencia oficial para el desarrollo, como se pide en el párrafo e) del séptimo compromiso y como se recomienda en el párrafo $11 \mathrm{~h}$ ) del Programa de Acción. En consecuencia, los Estados Unidos desean expresar reservas acerca del párrafo e) del séptimo compromiso y del párrafo $11 \mathrm{~h}$ ) del Programa de Acción. Ello no obstante, los Estados Unidos siguen empeñados en la labor de aceleración del desarrollo de África y de los países menos adelantados» (U.N. Doc. A/CONF. 166/9, cap. V, n. 17).

66. Y. TAmir, Yael Tamir Replies, en "Boston Review", 21 (1996), p. 32. La traducción es nuestra. Ofrece un valioso análisis de las discusiones entorno a esta práctica y su contextualización cultural, K. ENGLE, Culture and Human Rights..., cit., pp. 297-302.

67. Una exhaustiva exposición de tales reivindicaciones puede verse en M.K. ERIKSSON, Reproductive Freedom. In the Context of International Human Rights and Humanitarian Law, The Hague, 2000.

68. El gobierno peruano puso en marcha el Programa AQV (Anticoncepciones quirúrgicas voluntarias) para esterilizar entre los años 1996-1998 a un total de 400.000 personas, con cuotas explícitas anuales. Terminado el período previsto, el Comité de América Latina y el Caribe para la Defensa de los Derechos de la Mujer (CLADEM) ha publicado un informe sobre los resultados conseguidos en esos tres años bajo el título Nada personal. En contra de lo previsto en la Ley n. 26530 se ejercieron promesas y estímulos proporcionando a las mujeres alimentos, dinero y otros bienes; o ejerciendo amenazas cuando no se conseguía el objetivo; también existieron esterilizaciones contra la voluntad expresa de la mujer, o sin previa información. Paralelamente se eliminó la objeción de conciencia de los médicos en la Ley General de Salud.

En el caso de México, en enero del 2003, la Comisión Mexicana de Derechos Humanos, a través de un comunicado oficial, denunció que el Gobierno estaba violando las facultades de las mujeres indígenas y pobres al incluir en su programa de salud sexual y reproductiva métodos de esterilización forzosa.

69. M. Elósegui, Diez temas de género..., cit., p. 147, vid. también pp. 151-175. 
de algunas agencias especializadas de Naciones Unidas, especialmente del Fondo de Población (UNFPA) ${ }^{70}$.

Llegado este punto, se tiene la impresión de que mundialización e ideología del género, cada una desde sus respectivas posturas extremas uniformadoras, acaban cayendo en el mismo error: el de imponer una visión de la realidad como si fuera la única. Algunos feminismos del norte se están sirviendo de las Naciones Unidas y de sus Agencias especializadas para imponer una visión de la mujer, de la sexualidad y de la sociedad, ajena a los problemas más acuciantes de al menos dos tercios de las mujeres del mundo. Y esta brecha, que separa cada vez más ambos mundos, está siendo denunciada con fuerza y claridad por los feminismos del sur, que consideran esas políticas como racistas, sexistas e imperialistas, ajenas muchas veces a sus particularidades nacionales, culturales y religiosas ${ }^{71}$.

\section{CONCLUSIÓN}

Muchas cosas están cambiando con gran rapidez en el nuevo contexto mundial. El proceso de mundialización ha ocasionado cambios de política a favor de una mayor apertura a las corrientes financieras y comerciales, la privatización de empresas estatales y una reducción del gasto público, todo ello está transformando las pautas de producción y acelerando el avance tecnológico en las comunicaciones. Esos cambios están incidiendo también en los valores culturales, los estilos de vida y los medios de difusión. Estas tendencias han ido acompañadas de profundos cambios políticos, entre ellos nuevas formas de gobernalidad y la realización más universal de los derechos humanos. Sin embargo, no todas las mujeres se han beneficiado por igual de los efectos de la mundialización, para algunas ha significado mayores oportunidades económicas y mayor autonomía, pero a otras muchas las dejado en una situación más vulnerable ${ }^{72}$.

No faltan datos para considerar que en la actualidad las cuestiones relacionadas con el derecho a la identidad, del tipo que sea, acaban convirtiéndose en un tema envenenado. Se puede llegar hasta el extremo de invocar el derecho a la identidad cultural para atrincherarse en una discapacidad, como fue el caso de Sharon Duchesneau y Candy McCullough, dos lesbianas sordomudas que lograron tener un hijo también sordomudo mediante un tratamiento de fertilización in vitro. Comparto con Marina que existe una tendencia a ir más allá de las reivindicaciones justas y exhibir con orgullo el rasgo por el que uno es marginado, convirtiéndolo en una seña de identidad. Pero ser mujer $\mathrm{u}$ hombre no es fuente de derechos. Los derechos se tienen por ser persona,

70. Cfr. Financial Statements 2000, p. 33 [Disponible en: http://www.ippf.org (consulta: 28 de septiembre de 2001)].

71. Cfr. N. NAVARro, Los Derechos reproductivos en un contexto de liberalismo globalizador, cit. por M. Elósegui, Diez temas de género..., cit., pp. 143-145. Vid. también L.A. OBIORA, Feminism, Globalization, and Culture: After Beijing, en "Indiana Journal of Global Legal Studies", 355 (1997), pp. 388-393.

72. Cfr. Nuevas medidas e iniciativas para aplicar la Declaración y la Plataforma de Acción de Beijing. Proyecto de documento presentado por la Presidenta del Comité Preparatorio del períoo extraordinario de sesiones de la Asamblea General titulado "La mujer en el año 2000: igualdad entre los géneros, desarrollo y paz para el siglo XXI”, New York, 2000 (U.N. Doc. E/CN.6/2000/PC/L.1, n. 29). 
condición común en la que radica la universalidad de los derechos humanos y fundamento último para prohibir cualquier discriminación injusta ${ }^{73}$.

Son evidencias desgraciadamente no siempre claras ni asumidas por la sociedad. Quizás por ello todavía es necesario tomar conciencia de que las actitudes y el comportamiento tanto de los individuos como de las instituciones deben cambiar para tener en cuenta los derechos y las necesidades reales de las mujeres.

73. J.A. MARINA, El Semanal, 28 de abril de 2002, p. 112. 